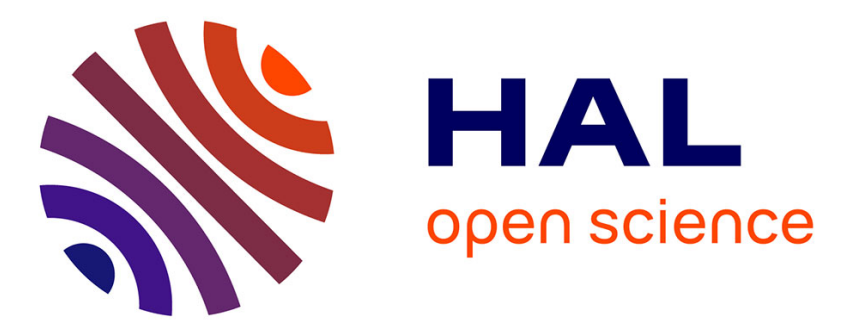

\title{
Stabilisation of sheep wool fibres under air atmosphere: Study of physicochemical changes
}

Ana Claudia Pina, Nestor Tancredi, Conchi Maria Concepcion Ovin Ania, Alejandro Amaya

\section{- To cite this version:}

Ana Claudia Pina, Nestor Tancredi, Conchi Maria Concepcion Ovin Ania, Alejandro Amaya. Stabilisation of sheep wool fibres under air atmosphere: Study of physicochemical changes. Materials Science and Engineering: B, 2021, 268, pp.115115. 10.1016/j.mseb.2021.115115 . hal-03433526

\section{HAL Id: hal-03433526 https://hal.science/hal-03433526}

Submitted on 18 Nov 2021

HAL is a multi-disciplinary open access archive for the deposit and dissemination of scientific research documents, whether they are published or not. The documents may come from teaching and research institutions in France or abroad, or from public or private research centers.
L'archive ouverte pluridisciplinaire HAL, est destinée au dépôt et à la diffusion de documents scientifiques de niveau recherche, publiés ou non, émanant des établissements d'enseignement et de recherche français ou étrangers, des laboratoires publics ou privés. 


\title{
Stabilisation of sheep wool fibres under air atmosphere: study of physicochemical changes
}

\author{
Ana Claudia Pina ${ }^{1,2}$, Nestor Tancredi $^{1}$, Conchi O. Ania ${ }^{2}$, Alejandro Amaya ${ }^{1, *}$ \\ ${ }^{1}$ Fisicoquímica, DETEMA, Facultad de Química, Udelar, 11800 Montevideo, Uruguay \\ ${ }^{2}$ CEMHTI, CNRS (UPR 3079), Université d'Orléans, 45071 Orléans, France.
}

*Corresponding author: aamaya@fq.ed.uy; conchi.ania@cnrs-orleans.fr Tel: 59829290770

\begin{abstract}
Natural fibres are abundant and renewable sources that constitute interesting alternative precursors to reduce the cost and environmental impact in the manufacturing of carbon fibres. However, they are prone to fuse and degrade upon thermal treatment, which strongly affects the morphology and stability of the prepared fibres. This study has analysed the chemical, structural and morphological transformations of wool fibres during the oxidative stabilization in air, to investigate their potential use as natural precursors for the production of carbon fibres. A thorough analysis of the fibres stabilized at mild temperatures has been carried out to follow the evolution of the O-, N- and Smoieties of the wool fibres during the oxidative stabilization. Below $400{ }^{\circ} \mathrm{C}$, the structure and morphology of the fibres was preserved, with important changes in the composition. Sulphur and oxygen contents decreased with the stabilization temperature due to decomposition and oxidation of S- and O- groups (e.g., cleavage of sulphur bridges, oxidative crosslinking). Nitrogen content remained rather constant regardless of the stabilization temperature and time, indicating a rearrangement of $\mathrm{N}$-groups most likely through the transformation of amides in carbodiimide groups. At $300^{\circ} \mathrm{C}$, dehydration reactions involving adjacent surface groups take place, causing the loss of the secondary structure of the fibres, while the polypeptide bonds remain unaffected. Data showed that the oxidative at $300{ }^{\circ} \mathrm{C}$ can render materials with a fibrous morphology and high carbon yield, susceptible of undergoing further carbonization at higher temperatures to obtain carbon fibres.
\end{abstract}




\section{Introduction}

Carbon fibres are lightweight materials with unique mechanical properties and high demand as consumer grade products for many different application fields including aerospace, textile, construction, adsorption, catalysis and energy storage [1-5], among others. Owing to the high cost and carbon footprint (energy-intensive) of the precursors commonly used to manufacture carbon fibres (e.g., polyacrylonitrile accounting for over $90 \%$ of current production, phenolic resins, polyimides) [6-8], their niche market is mostly limited to high-performance structural materials. To reduce the high production costs, environmental impact and dependence on fossil sources in the manufacturing of carbon fibres, the search for alternative precursors from renewable sources has become a largely investigated topic with academic and industrial importance [9]. Attempts towards more sustainable precursors for the synthesis of carbon fibres have mainly been directed to the use of biomass-derived precursors, polyolefins and natural fibres [10].

Natural fibres are cheap, abundant and renewable; most importantly, they can be produced at low cost in many countries -including developing ones- and allow the reutilization of wastes generated in different production sectors (i.e., sustainability of wastes management within a circular economy policy). Yet the drawback is the high cost associated to their extraction from plants, along with the high-energy demand of the melt spinning process for the fabrication of the fibres [11]. On the other hand, scarce studies report the use of natural fibres from animal origin (e.g., wool) as precursors of carbon fibres [12]. Despite the carbon content of wool is lower than that of polyacrylonitrile and other biomass-derived precursors (e.g., lignin, cellulose); due to their high protein content they are rich in heteroatoms, which could represent an advantage for particular purposes. Moreover, its relatively high sulphur prevents higher carbon loss during a thermal treatment. In addition, large amounts of wool fibre wastes are produced worldwide, and need to be disposed-off. Thus, wool fibres are an interesting natural sustainable alternative for the production of carbon fibres.

One of the main drawbacks of synthetic and cellulosic fibres is that during a thermal treatment, they fuse, decompose or degrade losing mechanical strength and morphology [13], so the choice of the thermal processing pathway of natural fibres will control the features of the resulting material. A common procedure for the preparation of a material with fibre morphology and the desired mechanical strength is based on performing an oxidative thermal stabilisation of the fibre precursor at mild temperature. The reactions involved during the oxidative stabilisation step are mostly cyclization of nitrile groups (when using polyacrylonitrile as precursor) and dehydrogenation of saturated $\mathrm{C}-\mathrm{C}$ bonds (for synthetic and cellulosic fibres). The original fibres are transformed into a cross-linked cyclized network of carbon-nitrogen rings. This new spatial disposition prevents the fusion of the fibres during further thermal treatments at high temperatures [11]. The mechanisms involved during the oxidative stabilisation of wool fibres are not yet clarified, as most of the studies have focused on their use for the preparation of highly porous activated carbon fibres [14], fabrics [12], and felts [15].

Considering this, the aim of this work is to investigate the oxidative stabilisation of wool fibres as precursors for the preparation of carbon fibres, by analysing in detail the chemical, morphological and structural transformations occurring during the oxidative treatment at various temperatures. The structure and morphology of the fibres were preserved for stabilization temperatures below $400{ }^{\circ} \mathrm{C}$, although the composition and type of functional groups changed. Sulphur and oxygen contents decreased with the stabilization temperature, whereas nitrogen content remained quite the same, indicating the decomposition of S- and O- moieties along with a rearrangement of N-groups. The 
thermal cleavage of di-sulphur bridges, crosslinking and loss of the secondary structure of the fibres are identified as the main reactions occurring during the oxidative stabilization. This information is critical to optimize the conditions that guarantee the preparation of materials with fibrous morphology and high carbon yield after the oxidative stabilisation (e.g., 60 wt.\% carbon content upon stabilization at $300^{\circ} \mathrm{C}$ ) and further carbonization at higher temperatures.

\section{Experimental}

\subsection{Materials}

Sheep Merino wool fibres (WF) provided by the Uruguayan wool secretariat (S.U.L.) were used as precursor. The as-received wool fibres (ca. $29 \mu \mathrm{m}$ diameter) were already clean and spun.

\subsection{Oxidative Stabilisation}

The oxidative stabilisation of the as-received wool fibres was carried out under air atmosphere $\left(100 \mathrm{~mL} \mathrm{~min}^{-1}\right.$ ) at temperatures ranging from 200 to $300{ }^{\circ} \mathrm{C}$ (heating rate $15{ }^{\circ} \mathrm{C} \mathrm{min}^{-1}$ ) and oxidation times between 30 to 120 minutes. The fibres were placed inside a tubular horizontal furnace (CARBOLITE) by rolling them up around a stainless steel hollow cylindrical mesh (ca. $4 \mathrm{~cm}$ diameter, $23 \mathrm{~cm}$ length). After the stabilisation, the samples were cooled down to ambient temperature under $\mathrm{N}_{2}$ atmosphere flow (ca. $100 \mathrm{~mL} \mathrm{~min}^{-1}$ ). The obtained stabilised samples were labelled as SF-T-t, where $T$ and $t$ stand for the temperature and time, respectively, of the oxidative treatment.

\subsection{Characterisation}

Thermogravimetric analysis of the pristine and stabilised wool fibres was carried out on 6-25 mg of the material in a thermobalance (SHIMADZU TGA-50) under air and inert atmospheres (flow $100 \mathrm{mLmin}^{-1}$, heating rate $10{ }^{\circ} \mathrm{Cmin}^{-1}$ ) from room temperature up to $900{ }^{\circ} \mathrm{C}$, in a platinum crucible. To identify and quantify the gases evolved during the thermal decomposition of the materials, a thermobalance (NETZSCH STA 409 DC) coupled to a mass spectrometer was used; the thermogravimetric profiles were recorded under Ar atmosphere, and selected $\mathrm{m} / \mathrm{z}$ signals were recorded and quantified (e.g., $\mathrm{m} / \mathrm{z} 2,18,28,44,46,64)$. Elemental analysis of samples dried at $105{ }^{\circ} \mathrm{C}$ was measured in a LECO CHNS-932 (C, H, N, S) and a LECO-VTF-900 (O) analyzers. The $\mathrm{pH}$ at the zero point charge was determined following a reverse mass titration method [16] by $\mathrm{pH}$ measurements (METTLER TOLEDO). Fourier-transform infrared (FTIR) spectroscopy studies were carried out with a Bruker Vertex 80v, using materials dispersed in -and pressed with- dry $\mathrm{KBr}$ (spectroscopic grade) in a 1:100 ratio (w/w). Transmission spectra were carried out between 4000$350 \mathrm{~cm}^{-1}$ (64 scans collected, resolution $4 \mathrm{~cm}^{-1}$ ). Spectral data were recorded under vacuum to avoid the interference of ambient moisture and $\mathrm{CO}_{2}$. Raman spectra were recorded in ambient conditions in a spectrometer (RENISHAW INVIA REFLEX) equipped with a $355 \mathrm{~nm}$ laser, and using an optical microscope with x50 long (LEICA DM2500) working distance objective (ca. $10 \mathrm{~mm}$ ). Each spectrum was recorded with an integration time of $5 \mathrm{~s}$ in the $500-2400 \mathrm{~cm}^{-1}$ wavenumber range; the data presented represents the average of three measurements. Deconvolution of Raman spectra was carried out by a fitting procedure using a linear baseline and Gaussian/ Lorentzian functions. The morphology of selected samples was evaluated by scanning electron microscopy (JEOL JSM 5900L Scanning Electron Microscope); samples were observed as prepared, with metallic coating. 


\section{Results and discussion}

Before selecting the conditions for the oxidative stabilisation, the thermal features of the pristine wool fibres (WF) were studied in a thermobalance under oxidizing and inert atmosphere (Figure 1). A first mass loss below $100{ }^{\circ} \mathrm{C}$ observed in both atmospheres corresponds to the moisture of the wool fibres (ca. 1-3 wt.\%). Under inert atmosphere, a sharp mass loss is observed between 200$500{ }^{\circ} \mathrm{C}$, accounting for a ca. $60 \mathrm{wt} . \%$ of total mass loss. This feature is associated with the rupture of the hydrogen bonds of the peptide structure of the wool fibres, thereby undergoing condensation reactions rendering to a solid to melted phase change [13]. The temperature range is in agreement with other studies reporting the thermal decomposition of wool [17, 18].

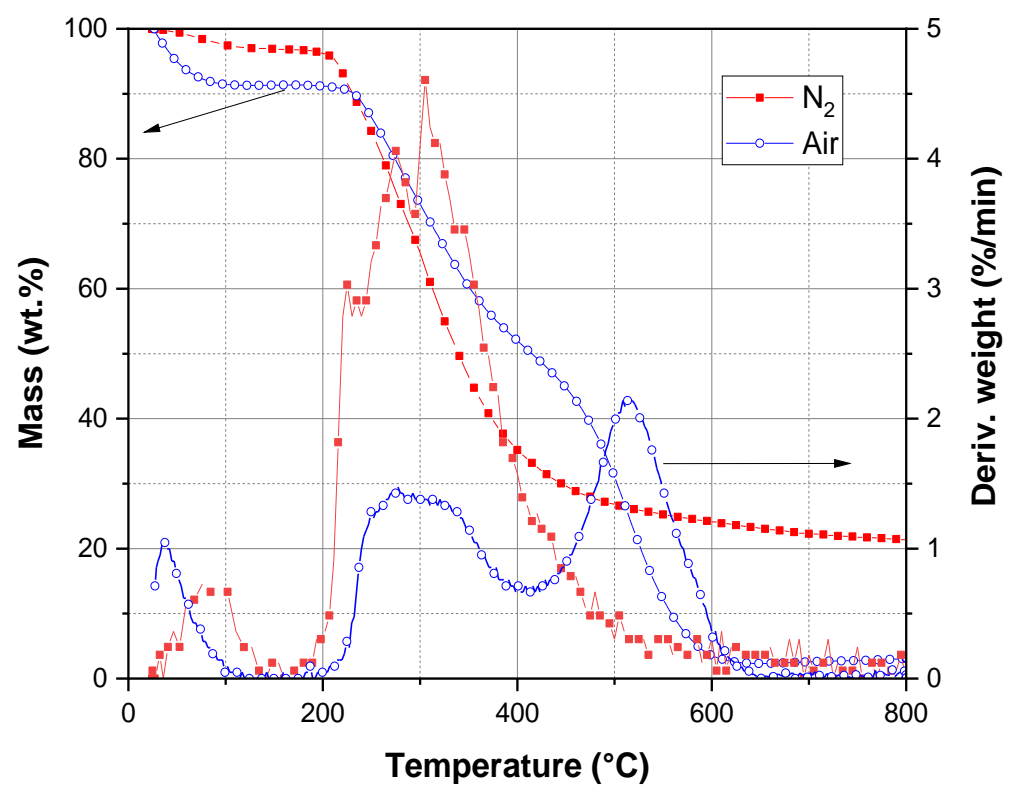

Figure 1. Thermogravimetric profiles (mass loss and derivative weight) under inert and air atmosphere of the pristine wool fibres.

In contrast, the profile in air showed two distinct thermal events in the range $200-400^{\circ} \mathrm{C}$ (Figure 1 ). Below $200^{\circ} \mathrm{C}$, the mass loss was negligible, pointing out the threshold oxidative temperature of the WF; a similar thermal fingerprint has been reported for several natural fibres [11]. The mass loss in air between $225-375^{\circ} \mathrm{C}$ accounted for ca. $40 \mathrm{wt} . \%$ of the overall mass loss. This has been associated with cyclization and saturation reactions [11]. Above $480{ }^{\circ} \mathrm{C}$, the mass loss rate increased (ca. 1.5 times faster compared to the first thermal event below $400^{\circ} \mathrm{C}$ ) reaching a complete mass loss, characteristic of a combustion reaction. Based on the thermogravimetric profiles in air, a range of temperatures between $225-300{ }^{\circ} \mathrm{C}$ was selected to explore the oxidative stabilisation of the wool fibres under air atmosphere.

The thermal profiles in inert atmosphere of the wool fibres stabilised in air at various temperatures and residence times are shown in Figure 2. The samples are classified in two groups upon the final weight loss: G1 formed by samples SF-225-t, and SF-250-t; and G2 composed by samples SF-275-t and SF-300-t. As seen, the overall mass loss at $900^{\circ} \mathrm{C}$ decreased as the stabilisation temperature increased, following the trend: group G1 > group G2. The total mass loss of the fibres treated at 225 
and $250{ }^{\circ} \mathrm{C}$ (ca. 32 wt.\%) was 1.6 times lower than for those stabilised at 275 and $300{ }^{\circ} \mathrm{C}$ (ca. $53 \mathrm{wt} . \%)$, regardless of the stabilisation time.
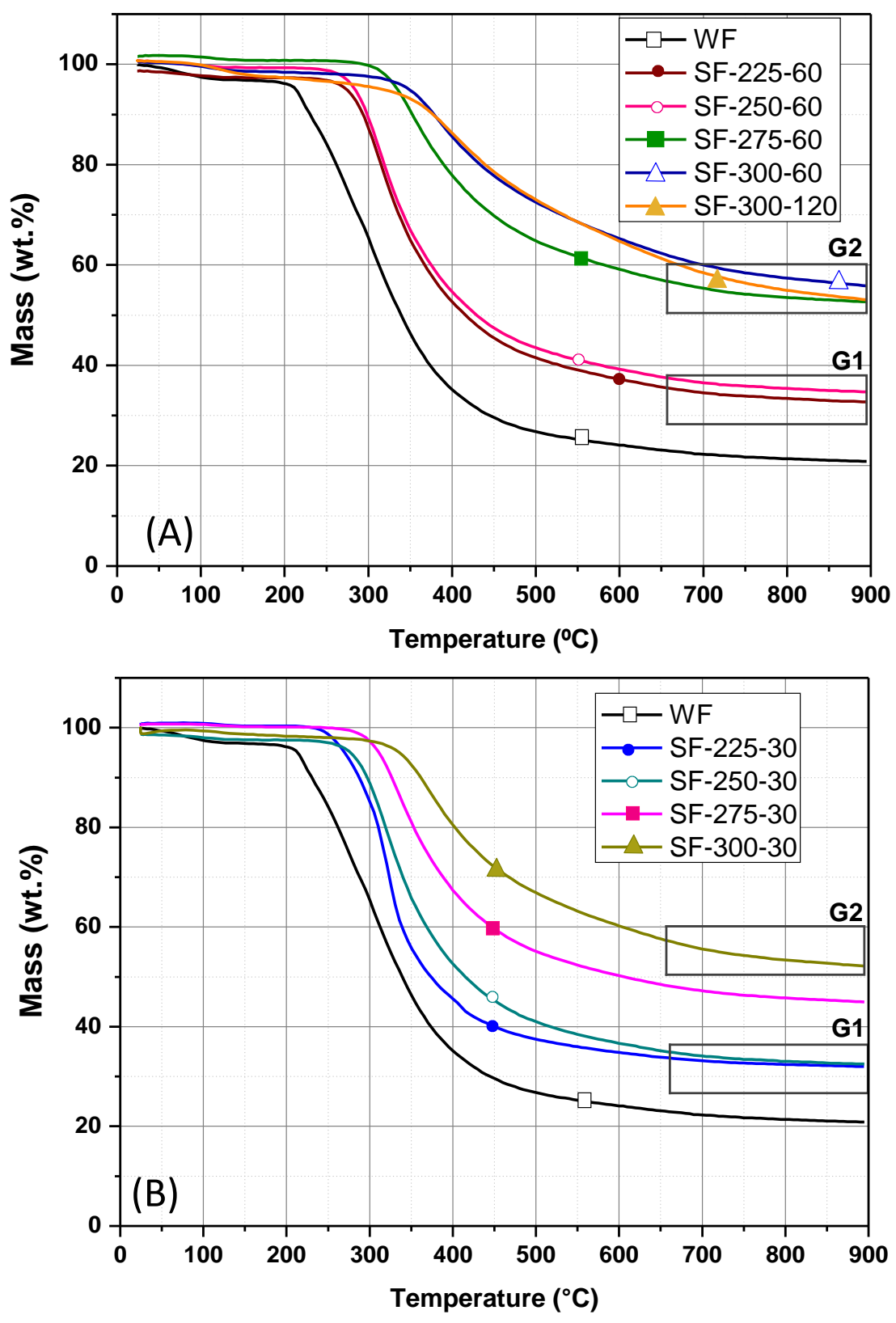

Figure 2. Thermogravimetric profiles under inert atmosphere of the wool fibres stabilised in air at various temperatures for (A) 60 and 120, and (B) 30 minutes.

The temperature corresponding to the main mass loss in the stabilised samples gradually moved towards higher temperatures, indicating that the stabilisation rendered indeed fibres more thermally stable than the pristine one. The mass loss occurring between $225-300^{\circ} \mathrm{C}$ is associated with the rupture of hydrogen-bond peptide helical structures, and the cleavage of disulphide bonds and the exothermic oxidation of the wool fibre, which is accompanied by solid-to-liquid phase changes (see calorimetric evidence in Fig. S1 in the Supplementary Information File) [19]. 
It should also be noticed that the obtained yields are higher than those reported upon chemical stabilisation of wool [12] or rayon fibres (ca. 20-30 wt.\%) [20], indicating a more effective oxidative stabilisation. This might be due to the composition of the pristine wool fibres, richer in di-sulphur bonds located at the cysteine residues (85 wt.\% keratin) [21], compared to cellulosic and synthetic polymeric fibres.

Regarding the stabilisation time, this parameter did not seem to impact strongly on the yields, with similar values (within 5\% difference) for the series treated at 30 and $60 \mathrm{~min}$. Only for the highest temperature (i.e., $300^{\circ} \mathrm{C}$ ) the reaction rate seemed to be independent of the time framework, with no significant differences in the yields for the samples stabilised at 30, 60 and $120 \mathrm{~min}$.

The elemental composition of selected stabilised fibres is compiled in Table 1. The carbon content increased with oxidative stabilisation, at the expense of the decrease in hydrogen, oxygen and sulphur. Interestingly, the nitrogen content remained rather constant. In contrast, the sulphur content decreased with both the oxidation temperature and time, except for the samples treated at $300{ }^{\circ} \mathrm{C}$ that showed similar values for different times. The reduction in the sulphur content is linked to the oxidation of di-sulphur bonds of the cysteine residues in the wool that would decompose in the form of hydrogen sulphide and sulphur dioxide [22]. The decrease in oxygen and hydrogen contents with the stabilisation temperature is mainly associated with dehydrogenation and dehydration reactions.

Table 1. Chemical composition (wt.\%, dry-ash free basis) of the pristine wool and the samples obtained after oxidative stabilisation at various temperatures and time.

\begin{tabular}{llllll}
\hline Sample & N & C & H & S & O \\
\hline WF & 15.45 & 49.03 & 6.97 & 3.04 & 25.52 \\
SF-225-60 & 15.48 & 51.58 & 6.19 & 1.94 & 24.81 \\
SF-250-60 & 15.59 & 54.79 & 5.69 & 1.54 & 22.03 \\
SF-275-60 & 15.87 & 58.12 & 4.91 & 1.25 & 19.85 \\
SF-300-60 & 15.83 & 60.50 & 4.15 & 1.15 & 18.36 \\
SF-300-120 & 15.89 & 62.54 & 4.09 & 1.18 & 16.29 \\
\hline
\end{tabular}

The infrared spectra of the fibres showed important differences upon the stabilisation. The characteristic signal at 2960 and $2920 \mathrm{~cm}^{-1}$ associated with $\mathrm{CH}$ groups was observed in all the samples. The band featured at $1111 \mathrm{~cm}^{-1}$, present in all the samples is assigned to $\mathrm{O}-\mathrm{C}$ stretching vibrations. The band at $\sim 740 \mathrm{~cm}^{-1}$ was assigned to the presence of esters for SF-250 series onwards. The broad band between $4000-3000 \mathrm{~cm}^{-1}$ can be interpreted as two contributions corresponding to N$\mathrm{H}$ stretching vibration $\left(\sim 3300 \mathrm{~cm}^{-1}\right)$ Amide A, and to $\mathrm{O}-\mathrm{H}$ stretching $\left(\sim 3200 \mathrm{~cm}^{-1}\right)$. In both cases, the frequency registered corresponds to H-bonded groups [18]. This band is observed for all the samples, regardless the temperature and time of the oxidative stabilisation. On the other hand, Amide B (Fermi resonance doublet $\sim 3100 \mathrm{~cm}^{-1}$ ) peak, also related to $\mathrm{N}-\mathrm{H}$ stretching vibrations, was no longer detected for sample SF-250-60 onwards. Amide I features $\left(\mathrm{C}=\mathrm{O}\right.$ stretching band $\left.\sim 1650 \mathrm{~cm}^{-1}\right)$ were observed in the pristine fibres and up to the series SF-250 at the same frequency. Whereas amide II (out of phase combination of the $\mathrm{NH}$ in plane bend and the $\mathrm{CN}$ stretching vibration $\sim 1500$ $\mathrm{cm}^{-1}$ ) and amide III (in phase combination of the $\mathrm{NH}$ bend and the $\mathrm{CN}$ stretching vibration, $\sim 1235$ $\mathrm{cm}^{-1}$ ) were not detected for any of the samples stabilised at $300{ }^{\circ} \mathrm{C}(\mathrm{SF}-300$ series). Amide IV $(\mathrm{C}=\mathrm{O}-$ $\mathrm{N}$ bending mode $\sim 620 \mathrm{~cm}^{-1}$ ) was detected for all samples [23]. Thus, even though the signals associated with $\mathrm{N}-\mathrm{H}$ and $\mathrm{C}-\mathrm{N}\left(1200-1400 \mathrm{~cm}^{-1}\right)$ bonds are present in all the samples, there are 
important differences in the nature of the groups. This is in agreement with the trend observed for the nitrogen content by elemental analysis (Table 1), and confirms that the $\mathrm{N}$-groups are predominantly rearranged during the oxidation. On the other hand, the lack of Amide I and II groups for the samples stabilized at $300{ }^{\circ} \mathrm{C}$ indicates the occurrence of conformational changes in the secondary structure of the fibres, most likely associated with the evolution of hydrogen bonds during dehydration reactions [23].

A similar trend has been reported for the conversion of amino groups into amide bonds during crosslinking reactions [24] and is consistent with the high content of amino acids in wool fibres. Such rearrangement of the N-moieties is supported by the appearance of a peak at $2221 \mathrm{~cm}^{-1}$ for sample SF-275 and onwards series, associated with carbodiimide bond (-N=C=N-). Carbodiimides are usually formed via isocyanates $(-\mathrm{N}=\mathrm{C}=\mathrm{O})$ as intermediate sub product in the oxidation of amines. In the case of proteins, two amino acid residues close to each other in the tertiary structure can form isocyanates, and these can undergo into carbodiimides generating new bonds between protein chains. The appearance of this group correlates with the gradual change observed in the $2500-1700 \mathrm{~cm}^{-1}$ range, indicating the presence of a new group.

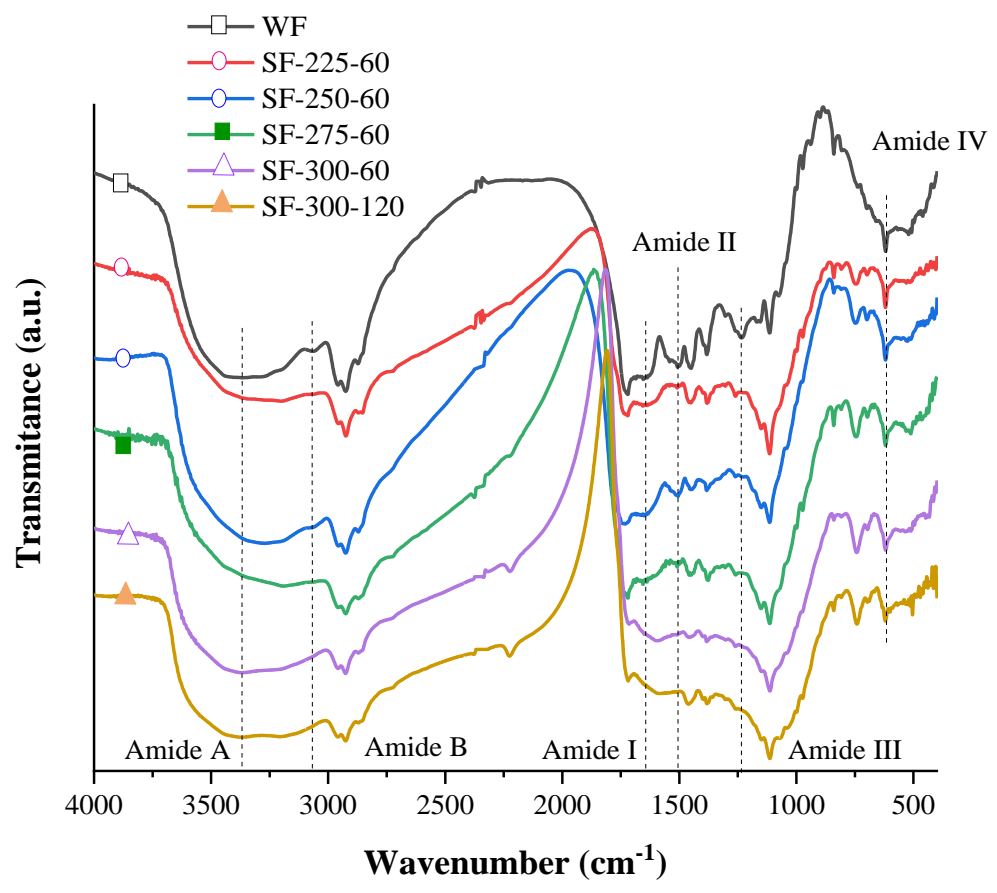

Figure 3. Infrared spectra of the pristine wool fibre and the series of samples stabilised at 60 and 120 minutes at various temperatures.

Sulphur containing groups are difficult to detect by FTIR analysis as they often appear as low intensity and nearby lying bands. To facilitate the identification of overlapped bands not resolved in the original spectra, we performed a derivative analysis of FTIR data [25]. As seen in Figure 4, the disulphide bonds stretching vibration band at $\sim 522 \mathrm{~cm}^{-1}$ is detected for all samples, although it appears slightly shifted to higher frequencies for SF-300 series $\left(\sim 524 \mathrm{~cm}^{-1}\right)$. As the wool is oxidized, structural changes could be expected in the cysteine residues. The bands at ca. 1020 and $1040 \mathrm{~cm}^{-1}$ can be assigned to cysteine-sulphonate moieties (Bunte's salt) and cysteic acid, respectively; both were detected for WF with SF-300-60. On the other hand, cysteine monoxide and dioxide, featuring at 1076 and $1121 \mathrm{~cm}^{-1}$ respectively, were observed only for SF-300-60. These frequencies are in 
agreement with reported data for plasma treatment of wool fibres [24], and thus confirm the oxidation of sulphur moieties upon the stabilisation in air.
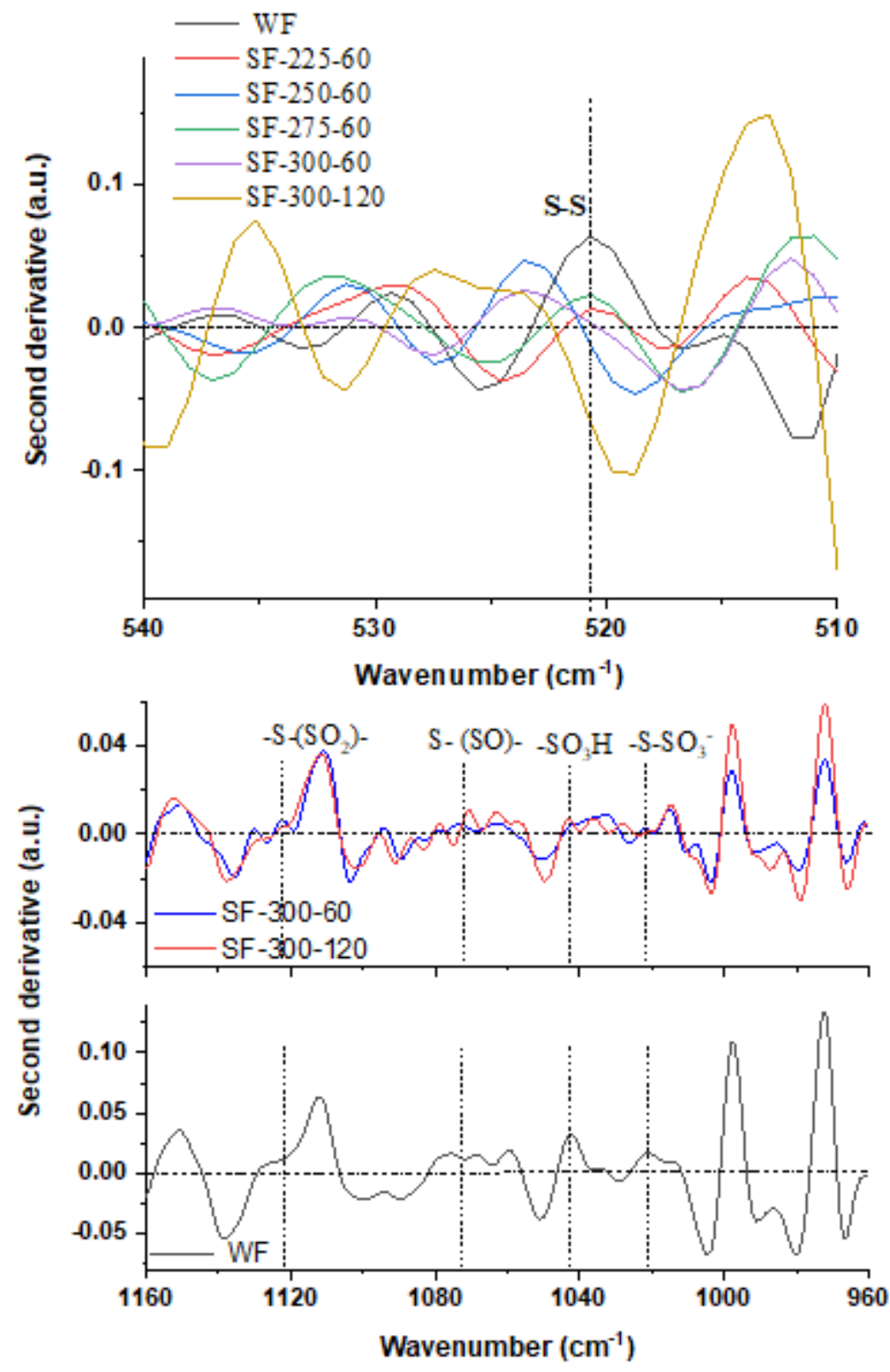

Figure 4. Second derivative of the FTIR transmittance spectra of selected samples.

Additional characterisation of the changes in the wool fibres upon the oxidative stabilisation was carried out by temperature programmed desorption coupled to mass spectrometry, and the identification of the evolved gases in the samples. Figure 5 shows the profiles corresponding to the $\mathrm{m} / \mathrm{z} 2,18,28,44,46$, and 64 of the thermogravimetric profiles recorded in argon atmosphere. 
a)

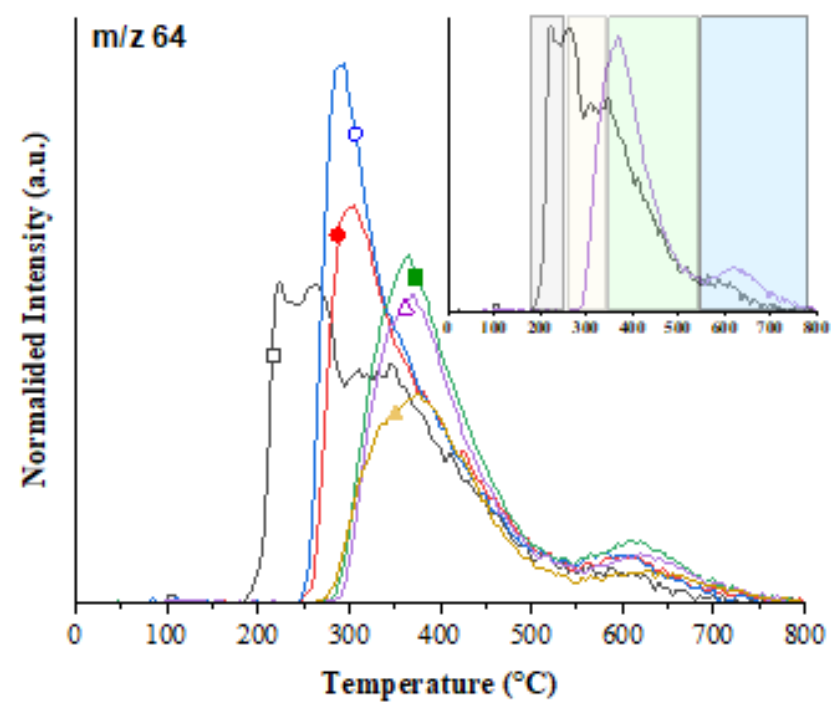

c)

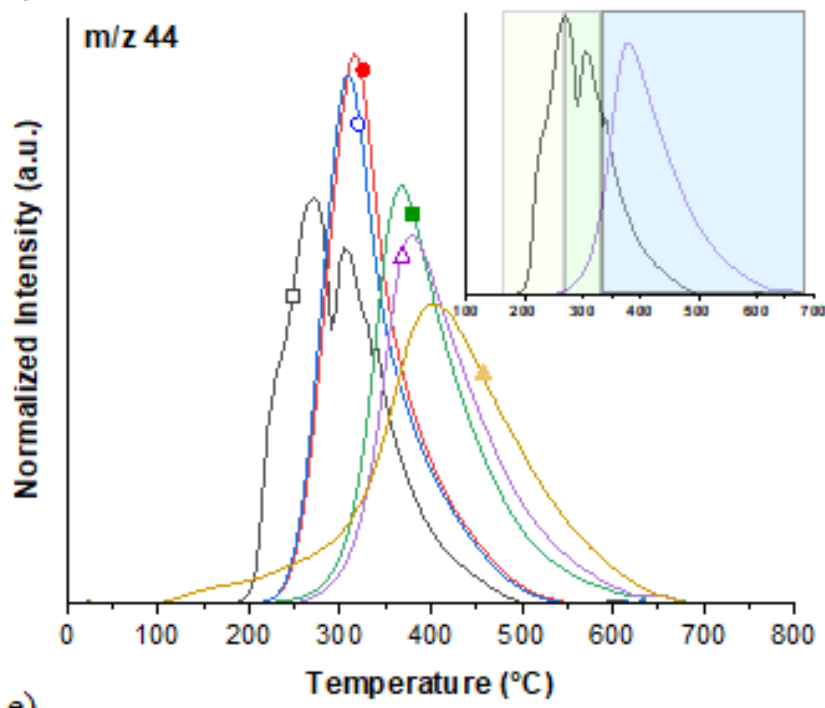

e)

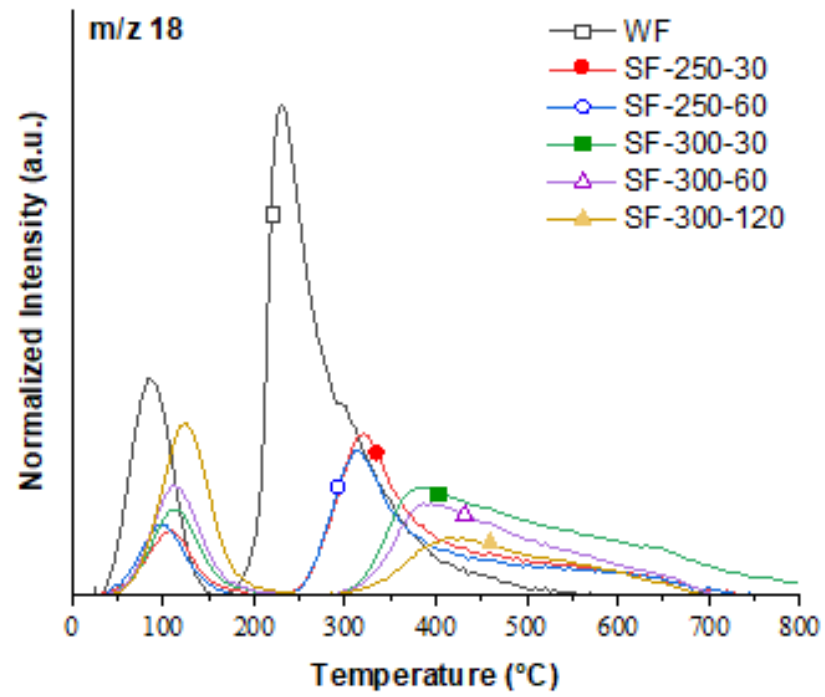

b)

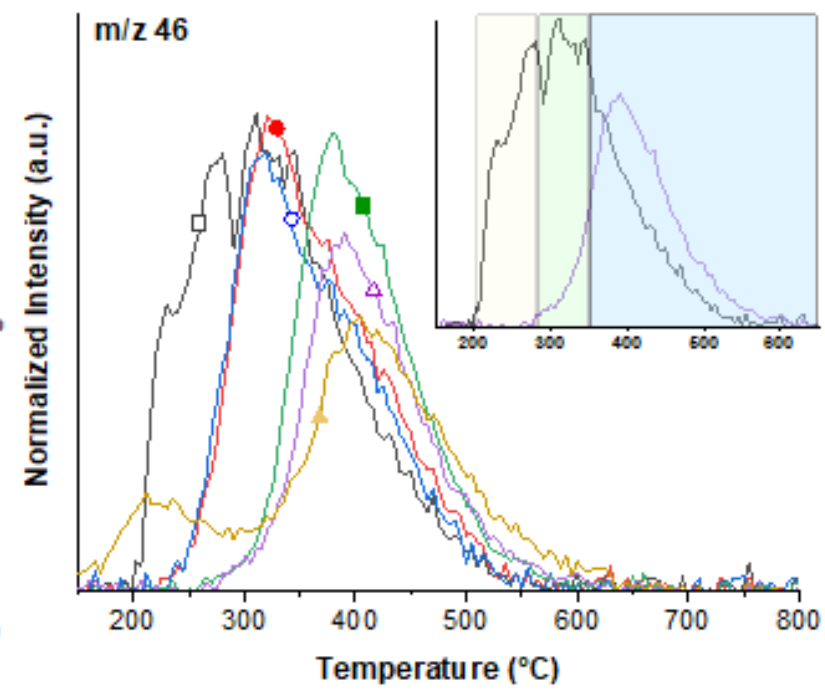

d)
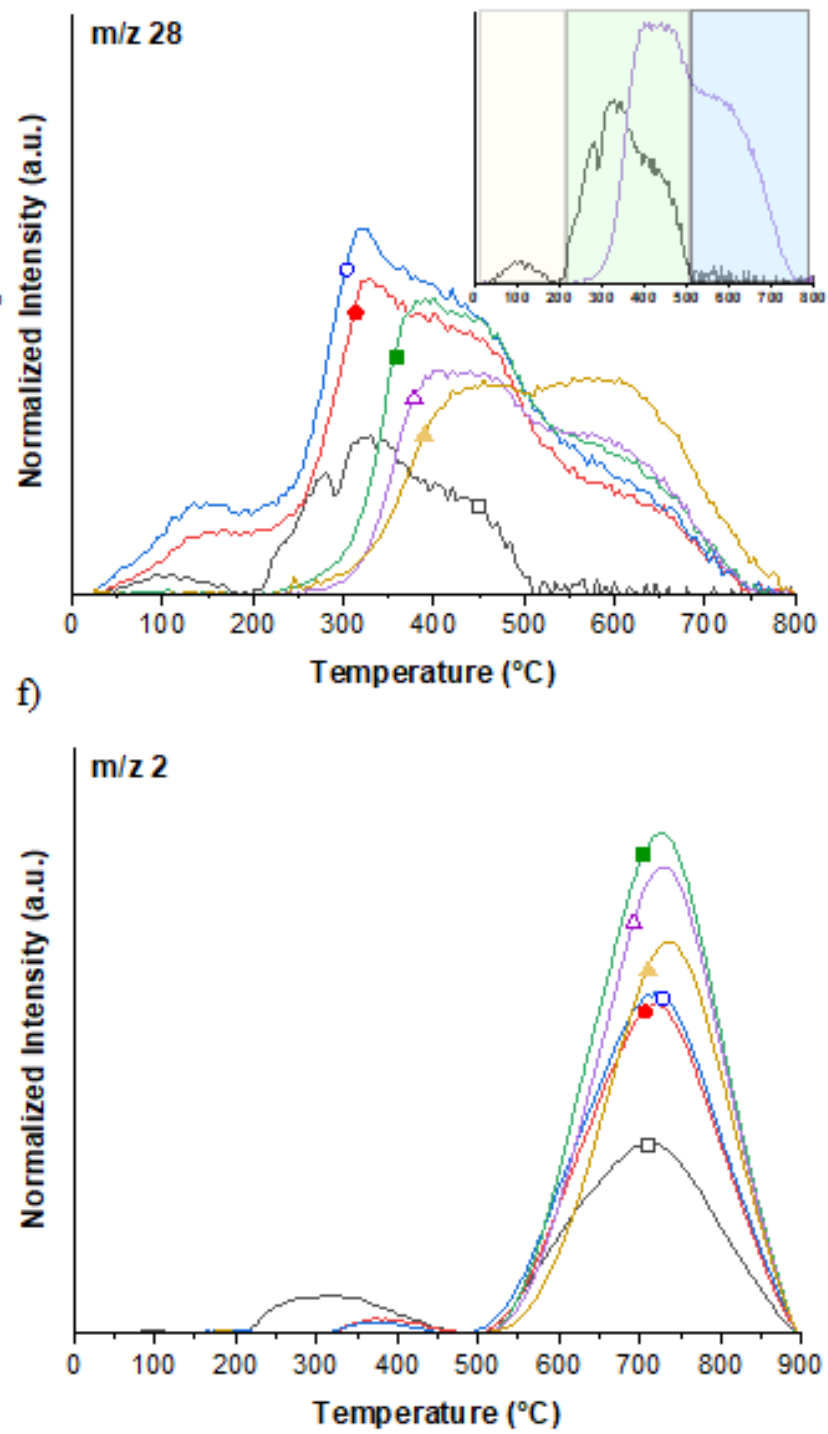

Figure 5. TPD-MS profiles of selected $\mathrm{m} / \mathrm{z}$ for the pristine and stabilised wool fibres. Insets illustrate differentiated emission zones for WF and SF-300-60. 
The evolution of signal m/z 64 (Figure 5 a) shows a broad emission band in the pristine wool fibres, spanning from $200-700{ }^{\circ} \mathrm{C}$. The multi-feature profile suggests that all released sulphur is bonded to the carbon surface in various configurations/environments. According to literature, $\mathrm{m} / \mathrm{z} 64$ is assigned to sulphur-carbon complexes in thiol, sulphide or oxidized forms of carbon $[25,26]$. This is due to the high reactivity of thiol and sulphide configurations that can be easily oxidized into $\mathrm{SO}_{2}$ evolving groups upon heating during the TPD assays.

To clarify the different contributions of the profiles, we performed a deconvolution of $\mathrm{m} / \mathrm{z} 64$ considering four thermal events (see insets in Figure 5) assigned to: thiol groups (ca. 180-250 ${ }^{\circ} \mathrm{C}$ ), disulphur (ca. $250-350^{\circ} \mathrm{C}$ ), and oxidized sulphides (ca. 350-500 and 550-700 ${ }^{\circ} \mathrm{C}$ ) $[27,28]$. The first peak between $185-250{ }^{\circ} \mathrm{C}$, only observed for $\mathrm{WF}$ is associated with thiol groups belonging to cysteine residues $(-\mathrm{SH})$. Above $200{ }^{\circ} \mathrm{C}$, thiols would be transformed into disulphur bonds (cystine type). The peak at 255 and $377^{\circ} \mathrm{C}$ in WF can be associated with thiol groups present in methionine residues and as sulphur from cystine. The peaks at higher temperatures in WF would correspond to the presence of oxidized sulphur groups, such as cystine sulphonate $\left(-\mathrm{SSO}_{3}{ }^{-}\right)$and cysteic acid $\left(-\mathrm{SO}_{2} \mathrm{OH}\right)$ as evidenced by FTIR (Figure 4). For the samples stabilised at $250{ }^{\circ} \mathrm{C}$ (series SF-250-t), the contribution of disulphur bonds is still observed $\left(250-350^{\circ} \mathrm{C}\right)$, with no evidence of thiol groups. The wide tail in the range $350-600{ }^{\circ} \mathrm{C}$ indicates oxidized forms of sulphur in different configurations; most likely esters, cystine monoxide, and cystine dioxide, in agreement with infrared data (Figures 3 and 4). For the samples stabilised at $300{ }^{\circ} \mathrm{C}$ (SF-300-t series), the contribution of unoxidized forms of sulphur can be discarded; for these samples, the main peak at $\sim 400{ }^{\circ} \mathrm{C}$ suggests oxidized sulphur in various configurations (e.g. cystine monoxide to dioxide). Finally, a small peak centred at $610{ }^{\circ} \mathrm{C}$ is visible to all samples, although its contribution becomes higher with the temperature of stabilisation. A semi quantitative analysis inferred from the evolution of the areas of the peaks (Figure 6a) shows that the overall $\mathrm{m} / \mathrm{z} 64$ signal decreased for the stabilised samples. This is in agreement with the decrease in sulphur content detected by elemental analysis (Table 1).

The $\mathrm{m} / \mathrm{z} 46$ signal was assigned to nitrogen moieties decomposing as $\mathrm{NO}_{2}$; the evolution for the stabilised samples also showed interesting features (Figure 5b). Deconvolution of the main peak was carried out considering three regions: $200-300{ }^{\circ} \mathrm{C}, 300-350{ }^{\circ} \mathrm{C}$, and $350-550{ }^{\circ} \mathrm{C}$. As in the case of $\mathrm{m} / \mathrm{z}$ 64, pristine wool fibres showed the largest contribution (Figure 6a) in the entire interval. The normalized intensities of the $\mathrm{m} / \mathrm{z} 46$ signal did not vary much for the samples, although the profiles shifted towards higher temperatures with the stabilization temperature. This correlates with the data from elemental analysis (Table 1) where the nitrogen content remained rather unchanged. It suggests that $\mathrm{N}$-containing groups mainly suffer structural/configuration modifications, rather than thermal decomposition upon the oxidative stabilisation. Taking into account that peptide bonds are very stable and that the amide groups are present for all samples (Figure 3), it may be inferred that the nitrogen in peptide bonds are not affected by the treatment. Therefore, the $\mathrm{m} / \mathrm{z}$ signal likely comes from residues rather than the main chain. The second region in SF-250-t series overlaps with that of $\mathrm{m} / \mathrm{z} 64$ (ca. $310{ }^{\circ} \mathrm{C}$ ), suggesting that it may be associated to the evolution of residues containing sulphur (cystine) linked to residues containing amines (e.g. arginine, proline, tryptophan). Furthermore, the shoulder at $390{ }^{\circ} \mathrm{C}$ clearly became a peak for SF-300-t series, implying a greater extent of oxidation. This peak temperature is in accordance with that corresponding to thermal degradation of carbodiimides, which presence was evidenced by FTIR and likely comes from oxidized primary amines (e.g. alanine, glycine, and isoleucine) [29]. 
The $\mathrm{m} / \mathrm{z} 44$ signal is typically assigned to $\mathrm{CO}_{2}$ evolving groups (Figure $5 \mathrm{c}$ ); deconvolution also shows three zones: $180-290{ }^{\circ} \mathrm{C}, 290-340{ }^{\circ} \mathrm{C}$, and $340-700{ }^{\circ} \mathrm{C}$. Unlike $\mathrm{m} / \mathrm{z} 64$ and 46 , the profile of WF did not show the third contribution, indicating that the highest temperature peak is due to products of oxidation of the fibres. The first peak, only featured for WF, could correspond to residues with carboxylic groups (aspartic and glutamic acids). The second and the third zones would correspond to the emission of carboxylic groups, anhydrides, and lactones (serine residues), also supported by the contribution of $\mathrm{m} / \mathrm{z} 28$ signal. Figure $6 \mathrm{~b}$ shows that the amount of $\mathrm{CO}_{2}$ evolving groups remains rather constant for all the samples.

a)

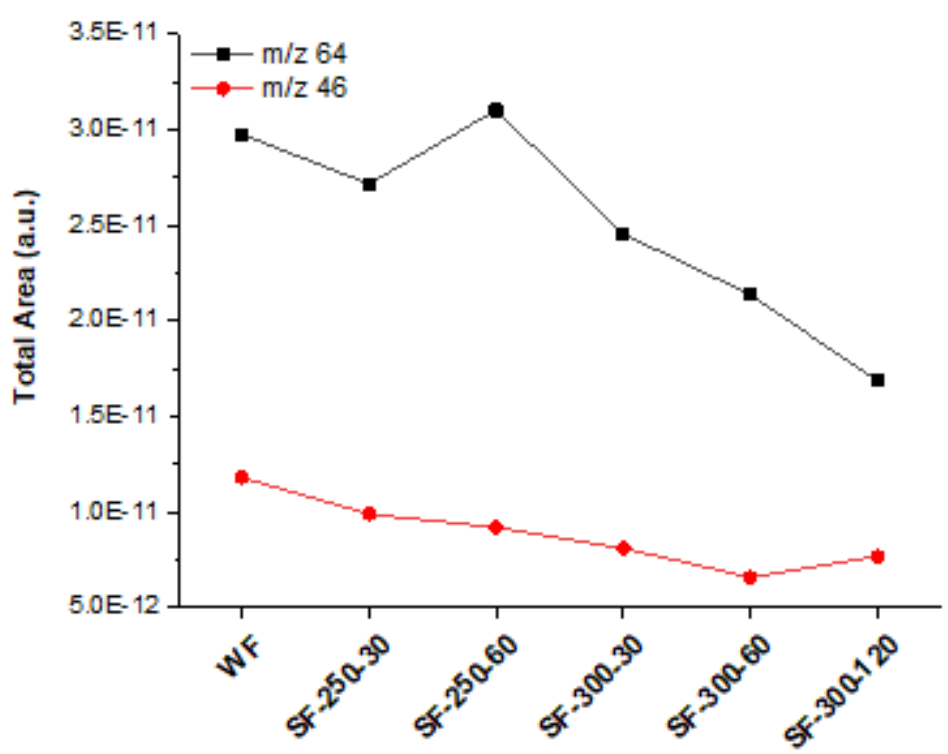

b)

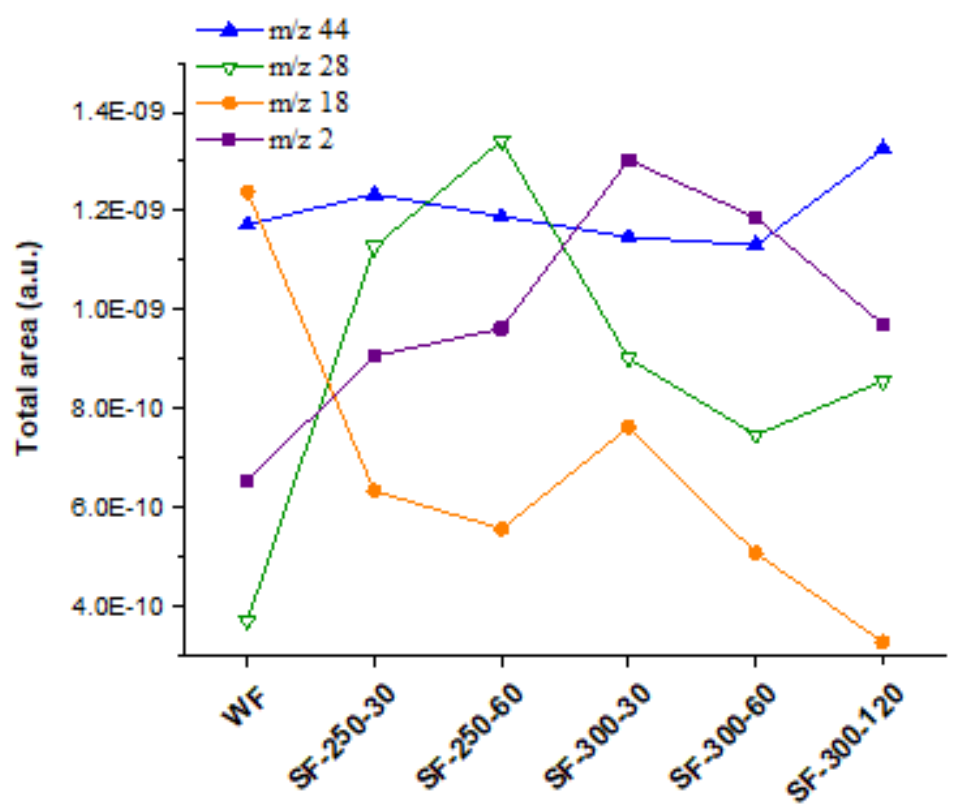

Figure 6. Total areas of the profiles corresponding to various $\mathrm{m} / \mathrm{z}$ signals obtained from TPD-MS data.

The $\mathrm{m} / \mathrm{z} 28$ signal is assigned to the evolution of CO, since TPD-MS experiments were carried out under argon atmosphere (Figure 5d). Three main zones can be distinguished: $200-300{ }^{\circ} \mathrm{C}, 300-$ 
$500{ }^{\circ} \mathrm{C}$, and $500-800^{\circ} \mathrm{C}$. The signal below $200{ }^{\circ} \mathrm{C}$ has no clear origin, although it has been attributed to the decomposition of vicinal carboxyl groups [30]. Interestingly, the shape of the curves changed with the stabilisation treatments, with peaks featuring at higher temperature as the stabilisation temperature increased; also, the amount of $\mathrm{CO}$ evolved showed a maximum for the series SF-250-t (Figure 6b). For these series, the main contribution corresponds to the second peak $\left(300-500{ }^{\circ} \mathrm{C}\right)$, whereas for series SF-300-t, it corresponds to the $500-800{ }^{\circ} \mathrm{C}$ zone. The latter can be related to carbonyl groups formed upon oxidation of threonine residues, quinones and ethers.

The release of water, m/z 18 signal (Figure 5e), was significant for all the samples, with several peaks in a wide range of temperatures between $100-700{ }^{\circ} \mathrm{C}$, due to the different dehydration reactions involving adjacent surface groups (e.g., carboxylic, hydroxyl groups) [32]. This is in agreement with the acidic character of the fibres (average $\mathrm{pH}$ values of ca. $4.8 \pm 0.2$ ), infrared data, and the detection of anhydrides in the $\mathrm{m} / \mathrm{z} 28$ and 44 profiles at similar temperatures). The contribution of $\mathrm{m} / \mathrm{z} 18$ evolved in the range $400-700{ }^{\circ} \mathrm{C}$ decreased for the SF-300-t series as the time of stabilisation increased. This can be connected to the lower presence of phenol groups, that would be oxidized to quinones [31]. The signal $\mathrm{m} / \mathrm{z} 2$ assigned to $\mathrm{H}_{2}$ is linked to the cleavage of $\mathrm{C}-\mathrm{H}$ and $\mathrm{N}-\mathrm{H}$ bonds (Figure 5e). The signal was recorded above $500{ }^{\circ} \mathrm{C}$ in all cases, as expected for samples with high volatile matter content.

The amounts of evolved $\mathrm{CO}$ and $\mathrm{CO}_{2}$ were quantified (Table 2); data showed relatively large quantities of both gases for all the stabilised fibres regardless of the stabilisation temperature. This indicates that the oxidative stabilisation creates O-containing groups with higher thermal stability, as also confirmed by the thermogravimetric analysis (Figure 1). The ratio $\mathrm{CO} / \mathrm{CO}_{2}$ increased up to $250{ }^{\circ} \mathrm{C}$ to then decrease for the treatments at $300{ }^{\circ} \mathrm{C}$, remaining rather constant. Since the amount of $\mathrm{CO}_{2}$ remains practically unchanged, this indicates that the stabilisation mainly favoured the formation of ethers and carbonyl/quinone groups.

Table 2. Quantification of the amounts of $\mathrm{CO}$ and $\mathrm{CO}_{2}$ released obtained by integration of the $\mathrm{m} / \mathrm{z}$ 28 and 44 peaks in the TPD profiles.

\begin{tabular}{|c|c|c|c|}
\hline Sample & $\mathrm{CO}\left(\mu \mathrm{mol} . \mathrm{mol}^{-1}\right)$ & $\mathrm{CO}_{2}\left(\mu \mathrm{mol} . \mathrm{mol}^{-1}\right)$ & $\mathrm{CO} / \mathrm{CO}_{2}$ \\
\hline $\mathrm{WF}$ & 1289 & 3602 & 0.36 \\
\hline SF-250-30 & 2918 & 3571 & 0.82 \\
\hline SF-250-60 & 3654 & 3532 & 1.03 \\
\hline SF-300-30 & 2023 & 3452 & 0.59 \\
\hline SF-300-60 & 1809 & 3444 & 0.53 \\
\hline SF-300-120 & 2061 & 3726 & 0.55 \\
\hline
\end{tabular}

The structural changes induced upon stabilisation of the fibres were analysed by Raman spectroscopy (Figure 7). It should be mentioned that samples WF and SF 200-225 presented a high fluorescence component that prevented to record the Raman spectra. The spectra corresponding to the samples stabilised above $250^{\circ} \mathrm{C}$ are shown in Figure 7 . The spectra of all the samples are quite similar, showing the typical fingerprint of disorganized carbon materials with the characteristic D and $\mathrm{G}$ bands (ca. 1360 and $1580 \mathrm{~cm}^{-1}$, respectively) [33]. The broad profiles of the $\mathrm{D}$ and $\mathrm{G}$ bands and the absence of second order spectra indicate the amorphous character (short-range order) of the fibres. The broadness of $\mathrm{G}$ band also confirmed this observation, with full width at half-maximum 
values (ca. 89-97) comparable to those reported for stabilised pitch fibres [34]; the values for D band are higher due to a large contribution of defects.

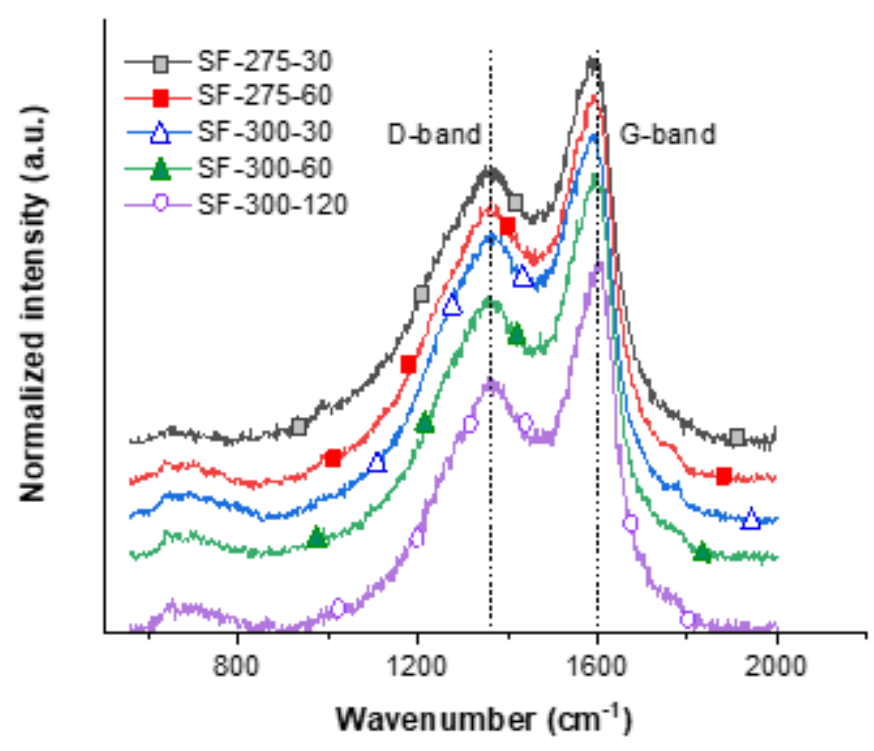

Figure 7. Raman spectra of selected stabilized samples; spectra have been shifted for clarity.

SEM (Figure 8) explored the morphology of the fibres upon stabilisation. For the pristine wool fibres, the two distinct zones of the precursor are observed: the inner marrow or cortex, and the external cuticle [21]. For the stabilised fibres, the characteristic cellular arrangement of the cuticle was still recognizable, although the surface gradually became smoother as the stabilisation temperature increased. While the fibrous morphology was preserved between $225-300^{\circ} \mathrm{C}$, the soft marrow gradually disappeared with the temperature. As it can be seen for sample SF-300-120, the stabilised fibres become hollow due to the loss of the cortex. The wall thickness of the hollow fibres was ca. $7.0 \pm 0.5 \mu \mathrm{m}$. On the other hand, the diameter of the fibres was barely modified during the stabilisation, with an average diameter for the pristine wool fibres of ca. $26 \mu \mathrm{m}$, and of about $29 \pm 2$ $\mu \mathrm{m}$ for sample SF-300-120. At stabilisation temperatures above $400{ }^{\circ} \mathrm{C}$, the fibrous morphology was no longer preserved, as the wool fibres melted (Fig. S2). Most interestingly, further carbonization of the stabilized fibres at high temperature under inert atmosphere (ca. 800-900 ${ }^{\circ} \mathrm{C}$ ) allowed to obtain carbon fibres with a well-preserved fibrous morphology and a high carbon content. In contrast, direct carbonization of the wool fibres (non-stabilized) provokes the loss of the fibrous morphology. 

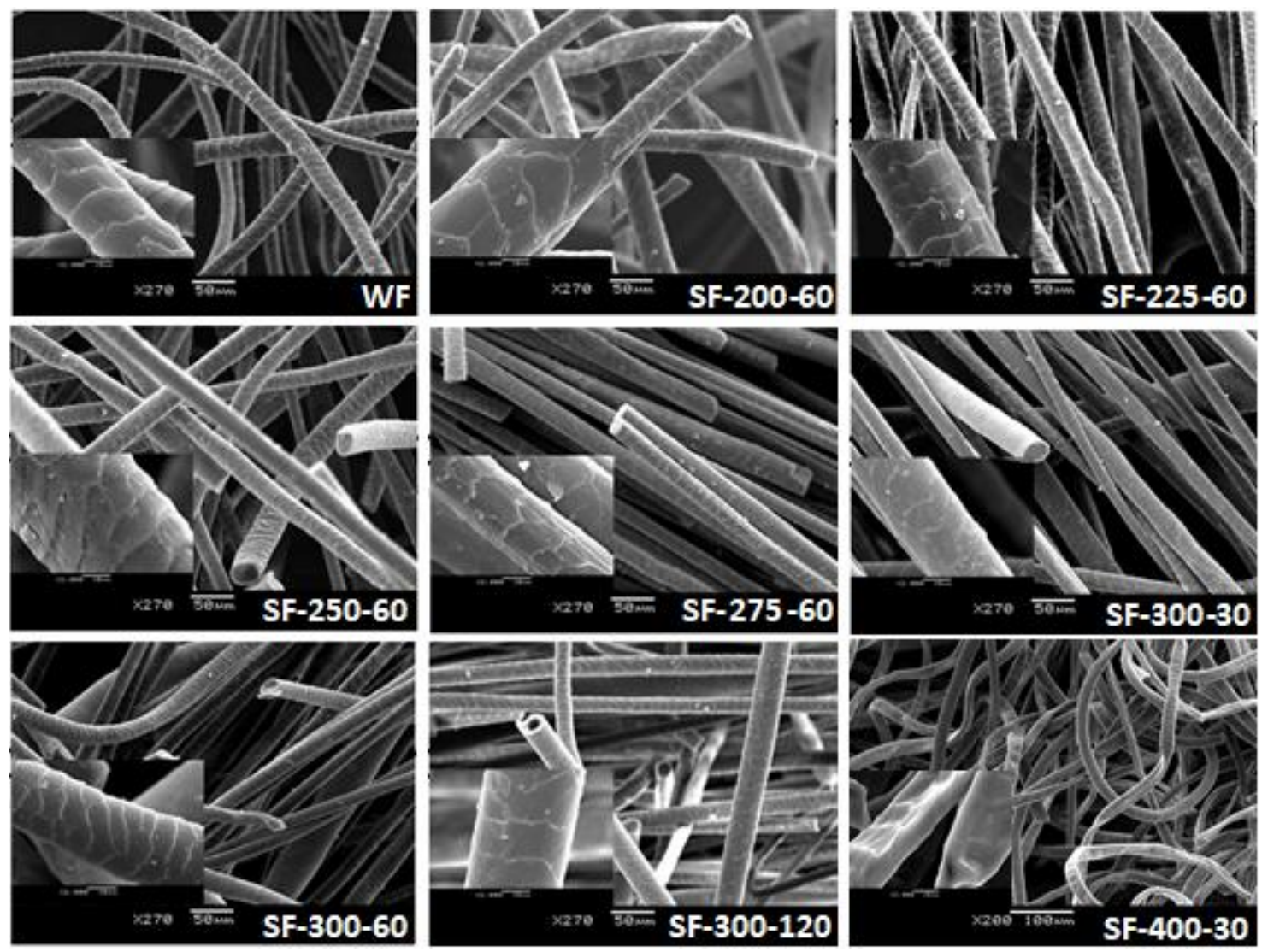

Figure 8. SEM images of the pristine and stabilized wool fibres at various temperatures (magnification of the images: $x 270 ; x 200$ for the insets).

\section{Conclusions}

The oxidative stabilization of wool fibres in air between $200-300{ }^{\circ} \mathrm{C}$ allowed to obtain densified materials with a fibrous morphology and a carbon content of up to $60 \mathrm{wt}$. $\%$. These stabilized fibres may be further carbonized at higher temperatures under inert atmosphere to increase carbon content and obtain carbon fibres (preserved fibrous morphology). Above $400{ }^{\circ} \mathrm{C}$, the morphology of the fibres is lost, and the material becomes fragile most likely due to the melting of the fibres. At lower temperatures, the morphology and structural features of the stabilized materials were rather similar, regardless of the stabilization conditions. A thorough characterization of the fibres stabilized up to $300{ }^{\circ} \mathrm{C}$ for different times has revealed important changes in the composition due to the thermal evolution of the O-, $\mathrm{N}$ - and $\mathrm{S}$ - moieties present in the pristine fibres. Overall, the sulphur and oxygen contents decreased with the stabilization temperature, whereas the nitrogen content remained rather constant. This indicates different thermal degradation pathways for the surface groups of the wool fibres. The loss of sulphur upon the decomposition and oxidation of sulphur bridges in the pristine fibres, leading to different oxidized sulphur complexes, still binding polypeptide chains in most cases. Thiols and disulphur bridged species present in the wool fibres (e.g., cysteine, methionine residues) are gradually transformed into various oxidized sulphur complexes (e.g., sulphonate, cystine monoxide, and dioxide residues). After stabilisation at $250{ }^{\circ} \mathrm{C}$, thiol groups are no longer observed but disulphur bonds are still detected. In contrast, for the samples stabilised at $300{ }^{\circ} \mathrm{C}$ sulphur is predominantly in oxidized complexes, with no evidence of thiols and a small contribution of disulphides. The amount of oxygen decreased, but remained relatively high in the stabilized fibres 
due to the formation of new groups (mainly ethers and quinone) during the cross-linking reactions occurring during the oxidative stabilization. Relatively large quantities of $\mathrm{CO}_{2}$ and $\mathrm{CO}$ were released regardless of the stabilisation temperature, due to the decomposition of carboxylic, ethers, and carbonyl groups present or formed upon oxidation of various residues (e.g., threonine, serine). On the other hand, the rearrangement of $\mathrm{N}$-groups would seem to be associated with the transformation of amides present in the pristine wool fibres into more stable carbodiimide groups. The release of water at various temperatures in the TPD-MS profiles confirmed the occurrence of dehydration reactions involving adjacent surface groups. This would be responsible for the loss of the secondary structure of the fibres. However, the polypeptide bond is not affected, and therefore, the primary structure remains unchanged. This allows to preserve the fibrous morphology of the stabilized materials.

\section{Acknowledgements}

This work was funded by ANII through a scholarship fund for national postgraduates (POS_NAC_2016_1_130887, PEDECIBA), and Region Centre Val de Loire (APR-IA, MOSAIK project). Ana Claudia Pina thanks CSIC for her scholarship to perform an internship in France.

\section{References}

1. Park S-J (2015), in Carbon Fibers, Springer Series in Materials Science, Vol. 210 Springer Dordrecht.

2. Hiremath N, Young S, Ghossein H, Penumadu D, Vaidya U, Theodore M (2020) Low cost textile-grade carbon-fiber epoxy composites for automotive and wind energy applications. Compos Part B Eng 108156. doi.org/10.1016/j.compositesb.2020.108156

3. Li H, Yang Y, Wen Y, Liu L (2007) A mechanism study on preparation of rayon based carbon fibers with (NH4)2SO4/NH4Cl/organosilicon composite catalyst system. Compos Sci Technol 67:2675-2682.

4. Al-Lami A, Hilmer P, Sinapius M (2018) Eco-efficiency assessment of manufacturing carbon fiber reinforced polymers (CFRP) in aerospace industry. Aerosp Sci Technol 79:669-678.

5. Mechtcherine V, Michel A, Liebscher M, Schneider K, Großmann C (2020) Mineralimpregnated carbon fiber composites as novel reinforcement for concrete construction: Material and automation perspectives. Autom Constr 110:103002.

6. Zhang SJ, Wang RM, Liao YQ (2019) A comparative study of two kinds of T800 carbon fibers produced by different spinning methods for the production of filament-wound pressure vessels. Xinxing Tan Cailiao/New Carbon Mater 34:578-586.

7. Khayyam H, Jazar RN, Nunna S, Golkarnarenji G, Badii K, Fakhrhoseini SM, Kumar S, Naebe M (2020) PAN precursor fabrication, applications and thermal stabilization process in carbon fiber production: Experimental and mathematical modelling. Prog Mater Sci 107:100575.

8. Sun Y, Sun Y (2020) Precursor infiltration and pyrolysis cycle-dependent mechanical and microwave absorption performances of continuous carbon fibers-reinforced boron-containing phenolic resins for low-density carbon-carbon composites. Ceram Int 46:15167-15175.

9. Ye W, Lin G, Wu W, Geng P, Hu X, Gao Z, Zhao J (2019) Separated 3D printing of continuous carbon fiber reinforced thermoplastic polyimide. Compos Part A Appl Sci Manuf 121:457-464. 
10. Milbrandt A, Booth S (2016) Carbon Fiber from Biomass. Clean Energy Manuf Anal Cent $1: 1-27$.

11. Torres-Canas F, Bentaleb A, Föllmer M, Roman J, Neri W, Ly I, Derré A, Poulin P (2020) Improved structure and highly conductive lignin-carbon fibers through graphene oxide liquid crystal. Carbon 163:120-127.

12. Hassan MM, Schiermeister L, Staiger MP (2015) Sustainable Production of Carbon Fiber: Effect of Cross-Linking in Wool Fiber on Carbon Yields and Morphologies of Derived Carbon Fiber. ACS Sustain Chem Eng 3:2660-2668.

13. Hassan MM, Schiermeister L, Staiger MP (2015) Thermal, chemical and morphological properties of carbon fibres derived from chemically pre-treated wool fibres. RSC Adv 5:55353-55362.

14. Pina AC, Tancredi N, Baldan M, Marcuzzo JS, Amaya A (2018) $\mathrm{CO}_{2}$ capture and biomethane obtention using activated carbon filter of animal origin. MRS Adv 3:3589-3600.

15. Pina A, Amaya A, Marcuzzo J, Rodrigues AC, Baldan MR, Tancredi N, Cuña A (2018) Supercapacitor Electrode Based on Activated Carbon Wool Felt. C 24:12.

16. Noh JS, Schwarz JA (1989) Estimation of the point of zero charge of simple oxides by mass titration. J Colloid Interface Sci 130:157-164.

17. Chen W, Liu X, He RL, Lin T, Zeng QF, Wang XG (2013) Activated carbon powders from wool fibers. Powder Technol 234:76-83.

18. Pakkaner E, Yalçın D, Uysal B, Top A (2019) Self-assembly behavior of the keratose proteins extracted from oxidized Ovis aries wool fibers. Int J Biol Macromol 125:1008-1015.

19. Cao J, Joko K, Cook JR (1997) DSC Studies of the Melting Behavior of $\alpha$-Form Crystallites in Wool Keratin. Text Res J 67:117-123.

20. Huang X (2009) Fabrication and properties of carbon fibers. Materials (Basel) 2:2369-2403.

21. Wojciechowska E, Włochowicz A, Wesełucha-Birczyńska A (1999) Application of Fouriertransform infrared and Raman spectroscopy to study degradation of the wool fiber keratin. J Mol Struct 511-512:307-318.

22. Savige WE, Maclaren JA (1966) Oxidation of disulfides, with special reference to cystine. In: Kharash N, Meyers CY (eds) The chemistry of organic sulfur compounds. Pergamon Press Inc., London, pp 367-402.

23. Parker, FS (1971) Applications of infrared spectroscopy in biochemistry, biology and medicine. Plenum Press, New York.

24. Chandwani N, Dave P, Jain V, Nema SK, Murkherjee S (2016) Experimental study to improve anti-felting characteristics of merino wool fiber by atmosphere pressure air plasma. Technical Report IPR/RR-776/2016, IPR LIBRARY, Bhat, Gandhinagar 382428. https://doi.org/10.13140/RG.2.1.2818.7281

25. Anthony JM (1988) Second derivative F.t.-i.r. spectra of celluloses I and II and related monoand oligo-saccharides. Carbohydrate Research, 173:185-195.

26. Puri BR, Hazra RS (1970) Carbon-sulphur surface complexes on charcoal. Carbon 9:123-134.

27. Gomis-Berenguer A, Seredych M, Iniesta J, Lima JC, Bandosz TJ, Ania CO (2016) Sulfur- 
mediated photochemical energy harvesting in nanoporous carbons. Carbon, 104:253-259.

28. Terzyk AP (2003) Further insights into the role of carbon surface functionalities in the mechanism of phenol adsorption. J Colloid Interface Sci 268:301-329.

29. Platnieks O, Gaidukovs S, Barkane A, et al (2020) Highly loaded cellulose/poly (butylene succinate) sustainable composites for woody-like advanced materials application. Molecules 25. https://doi.org/10.3390/molecules25010121

30. Feng W, Kwon S, Feng X, Borguet E, Vidic RD (2006) Sulfur impregnation on activated carbon fibers through $\mathrm{H}_{2} \mathrm{~S}$ oxidation for vapor phase mercury removal. J Environ Eng 3:292300 .

31. Hotová G, Slovák V, Soares OSGP, Figueiredo JL, Pereira MFR (2018) Oxygen surface groups analysis of carbonaceous samples pyrolysed at low temperature. Carbon, 134:255-263.

32. Figueiredo JL, Pereira MFR, Freitas MMA, Órfão JJM (1999) Modification of the surface chemistry of activated carbons. Carbon, 37:1379-1389.

33. Fries M, Steele A (2010) Raman spectroscopy and confocal Raman imaging in mineralogy and petrography. In: Dieing T, Hollricher O, Toposzi J (eds) Confocal raman microscopy. Springer, New York, pp 111-135.

34. Kim JD, Roh J-S, Kim M-S (2017) Effect of carbonization temperature on crystalline structure and properties of isotropic pitch-based carbon fiber. Carbon Lett 21:51-60. 